\title{
Antibodies in Cell and Their Biologic Reactions
}

\author{
Hideo Hayashi \\ Department of Pathology (Prof. H. Hayashi), \\ Kumamoto University Medical School, Kumamoto
}

\begin{abstract}
The cells, which were cultivated from the omentum of BAS-sensitized rabbits and grown in our special culture medium, contained antibodies to BSA, as detected by immunohistochemical and immunochemical methods. When the antigen (BSA) was introduced into the culture, the cells showed momentarily characteristic morphologic changes suggesting a decreased activity of cell membrane. The antibodies in the cells seemed to be due to $19 \mathrm{~S}$ antibodies, because the morphologic changes in the cells, passively sensitized with $19 \mathrm{~S}$ antibodies, were undoubtedly indistinguishable from those in the above actively sensitized cells. On the other hand, the cells, passively sensitized with $7 \mathrm{~S}$ antibodies, showed momentarily different morphologic changes suggesting an increased activity of the cell membrane. These observations possibly indicate an important relationship between the chemical structure and biologic action of these two antibodies to BSA. At present, we call the cells 'omentum cell'; and they may by very useful in the study of the formation and function of antibodies.
\end{abstract}

In previous studies, ${ }^{1-4}$ we have attempted to clarify a characteristic cellular injury occurring in the antigen-antibody reactions in tissue culture; and the morphologic changes in the cells were correlated with some biochemical changes; for instance, activation and release of a specific sulfhydryl-dependent protease (termed Arthus protease) and its inhibitor of polypeptide nature. The activation of the protease occurred in parallel with the morphologic changes in the cellular membrane (as described below) occurring immediately after contact with the antigen, and the release of the protease inhibitor seemed to be associated with those in the mitochondria and nuclei in the later stage of the reactions. Such morphologic sequences in the cells were also associated with the anaphylactic release of vascular permeability factors; and the release of the permeability factors seemed to be correlated with the activation of the cellular Arthus protease. 5,6

The biologically active substances listed above were isolated from the skin lesion of the antigen-antibody reactions, i.e., Arthus reactions, and intensively purified; and it was suggested that the balance between the specific protease and

Received for publication, February 9, 1966.

Delivered at the 5th General Meeting of the Japan Society of the Reticuloendothelial System, April 12, 1965, Fukuoka. 
its inhibitor may be one of the biochemical determinants of the antigen-antibody

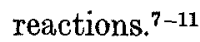

In the series of experiments described above, we have not yet confirmed directly the presence of antibodies in these cultured cells. Accordingly, the first part of the present report will concern this important problem.

\section{Immuno-histochemical and Immunochemical Demonstration of Antibodies in Cultured Cells}

The omentum pieces from BSA-sensitized rabbits were cultivated according to the previous method; and the cultivation was continued for several days. The cells grown in each culture were conventionally called the omentum cells ${ }^{12}$; there were observed to be spindle- and reticular-type cells. No other cell types were found in each culture. Since the spindle-type cells were occasionally observed to have changed to the reticular-type cells under the phase contrast microscope, it seemed possible that these cells were essentially identical and came from the same precursor cells of the omentum.

Antibodies, as shown by the Coon's fluorescent indirect method, were demonstrated in approximately 50-60 per cent of these grown cells; the specific fluoresence was distributed diffusely as very fine granules in the whole cytoplasm including the cytoplasmic processes varying in size but not in the nuclei. On the other hand, the omentum cells, similarly cultivated from the omentum of nonsensitizied normal rabbits, actively incorporated the antibodies (as pure gamma globulin isolated from the antisera of BSA-sensitized rabbits) into the cytoplasm; and the antibodies incorporated were detected as discrete granules varying in size; in particular they were localized in the perinuclear region of the cytoplasm, when tested by the Coon's fluorescent indirect method. Such differences in distribution of fluorescent antibody granules suggested that the omentum cells probably had produced in vivo antibodies to BSA.

In the omentum tissue not subjected to cultivation, there were revealed two types of fluoressence-positive cells; large mononuclear cells and plasma cells. The mononuclear cells seemed to be indistinguishable essentially from the cultured cells mentioned above; they appeared spindle or reticular in their form, and were found more abundantly than plasma cells.

The presence of antibodies in the cultured cells was furthermore confirmed immunochemically. The cells in culture were collected, homogenized and extracted with buffered saline $(\mathrm{pH} 7.6)$. The supernatant fluid after centrifugation was used as the antibody-containing cell extract.

The antibodies to BSA were confirmed by a quantitative precipitin reaction (in test tubes) and double diffusion test in agar. An ultracentrifugal assay (at 59,780 r.p.m.) of the cell extract suggested the presence of antibodies of $19 \mathrm{~S}$ and $7 \mathrm{~S}$ class, because these ultracentrifugal patterns clearly became lower when 
tested with the cell extracts, which was prepared similarly from the cells in which the antigen-antibody reactions had previously taken place. That is, these observations suggested the presence of antibodies of $19 \mathrm{~S}$ and $7 \mathrm{~S}$ classes in the omentum cells.

However; the question whether the omentum cells are concerned with the production of antibodies of these two classes must await further observation, because there was the possibility that the antibody of $7 \mathrm{~S}$ class, released from plasma cells of the original omentum pieces, might be mixed in the culture extracts. Fluorescence-positive plasma cells were contained in the original explants of the omentum, and it seemed possible that the plasma cells might release the antibodies during their degeneration in the culture. No growth of plasma cells was observed in any culture; and the cells fell in a marked degeneration shortly after the cultivation. All reports from many laboratories have shown the production of $7 \mathrm{~S}$ class antibody by plasma cells. Accordingly, there remained the question as to whether the omentum cells concerned only the production of $19 \mathrm{~S}$ class antibody. Furthermore, we shall have to clarify the fate of antibodies in the cultured omentum cells. Although the antibodies in the actively sensitized cells were detected for at least 7 days after cultivation, the antibodies in the passively sensitized cells could not be detected after 48 hours.

\section{Cine-microphotographic Demonstration of Antigen-antibody Reactions in Tissue} Culture

The second part of this report will concern the characteristic morphology of cellular antigen-antibody reactions in tissue culture. A cine-microphotograph under phase contrast was accomplished using a Zeiss Large Microcine Apparatus with an apochromat phase $1000 \times$ oil immersion objective, a monocular tube with a Zeiss $\mathrm{kpl} 10 \times$ ocular and an arriflex $16 \mathrm{~mm}$ motor-driven camera without lenses. Motion pictures were recorded at a speed of 30 frames per minute.

The cellular changes were characterized by a decrease or disappearance in the motion of cytoplasmic processes varying in size followed by their retraction, in the pinocytotic phenomenon accompanied by stopped undulatory motion of cytoplasmic borders, and in the movement of mitochondria and lipid granules. These morphologic changes were considered to indicate essentially a decrease or loss in the cellular membrane activity occurring immediately after contact with the antigen (BSA). In contrast to such primary changes described above, the secondary changes, which were initiated 50-60 minutes after the antigen administration, were characterized by granulation of filamentous or rod-shaped mitochondria, deformation of Golgi bodies and shrinkage of nuclei of these cells. Such morphologic changes in the actively sensitized cells were found approximately in 50-60 per cent of cultured cells. ${ }^{12}$

The primary changes described above were also demonstrated by another 
tissue culture experiment using labeled antigen (Congo red-azo-BSA); the omentum cells from non-seusitized normal rabbits ingested the labeled antigen in the form of large discrete red granules visible in the cytoplasm, when the labeled antigen was introduced into the culture, but the cells from sensitized rabbits primarily showed fine red granules distributed diffusely or arranged in filaments in cell membrane; such characteristic distribution of the labeled antigen in sensitized cells suggested that the union of the antigen and antibody primarily occurred in the cellular membrane. ${ }^{4,13}$

The third part of the present report will concern the problem of the biologic difference of antibodies of the $19 \mathrm{~S}$ and $7 \mathrm{~S}$ classes. The problem, which class of the antibodies is responsible for inducing the morphologic changes of cellular antigen-antibody reactions mentioned above seems to be of importance. A fraction of $19 \mathrm{~S}$ antibody was prepared from the antisera of BSA-sensitized rabbits by means of Sephadex G-200 gel filtration. Another fraction of $7 \mathrm{~S}$ antibody was prepared from the antisera by using DEAE-cellulose chromatography. The antibodies of each fraction were assayed immunochemically.

The cultured cells grown from the omentum of non-sensitized normal rabbits were passively sensitized with antibodies of $19 \mathrm{~S}$ and $7 \mathrm{~S}$ classes, respectively. After an incubation period of 30 minutes, antibodies in the culture medium fluid were removed by careful washing with Gey's buffered solution; the antibodies ingested by the cells were confirmed by Coon's fluorescent indirect method.

When the antigen (BSA) was applied to $19 \mathrm{~S}$ antibody-sensitized cells, there were clearly morphologic changes having the same aspects as those in the actively sensitized cells; the sequence of intracellular changes was indistinguishable from that in the actively sensitized cells. Accordingly, in the situation of cine-microphotographic observations, the characteristic morphologic changes in the actively sensitized cells may be due to $19 \mathrm{~S}$ antibody.

On the other hand, when the same antigen was applied to $7 \mathrm{~S}$ antibody-sensitized cells, there occurred clearly a different response in the passively sensitized cells. The morphologic changes were characterized by an increase in the cellular membrane activity, i.e., cellular excitation. This cellular excitation was demonstrated in the form of accelerated motion of cytoplasmic processes, increased pinocytosis with vigorous undulation of cytoplasmic borders, and increased movement of mitochondria and lipid granules. Such primary response in the $7 \mathrm{~S}$ antibody-sensitized cells was undoubtedly different from that seen in the $19 \mathrm{~S}$ antibody-sensitized cells; and this would suggest that the biologic differences between antibodies of $19 \mathrm{~S}$ and $7 \mathrm{~S}$ classes may be associated with their structural differences. For further explanation of this problem, similar experiments using the antibody subunits are being performed in this laboratory. 


\section{Acknowledgment}

The work presented here was performed in collaboration with Drs. M. Hisaka, S. Kudo, Y. Kinuwaki, T. Sonoda and S. Yamamoto. The work was aided by the grants from the Educational Ministry of Japan and the United States Army Research and Development Group, Far East.

\section{References}

1) Hayashi, H., Tokuda, A. \& Udaka, K. Biochemical study of cellular antigenantibody reaction in tissue culture. I. Activation and release of a protease. $J$. exp. Med., 1960, 112, 237-247.

2) Tokuda, A., Hayashi, H. \& Matsuba, K. Biochemical study of cellular antigenantibody reaction in tissue culture. II. Release of a protease inhibitor. $J$. exp. Med. 1960, 112, 249-255.

3) Hayashi, H., Tokuda, A., Ono, T. \& Takaba, Y. Biochemical and morphological studies of radiation injury in tissue culture; a comparison with cellular injury in antigen-antibody reactions. Brit. J. exp. Path., 1963, 44, 1-10.

4) Kuze, T. Cytological studies of antigen-antibody reaction in fibroblasts of adult rabbit by means of tissue culture. Mie-Igaku, 1960, 4, 1613-1624.

5) Hayashi, H., Kinuwaki, Y., Koono, M. \& Takaba, Y. The release of vascular permeability factors by homologous antigen and by soluble antigen-antibody complexes in tissue and its biologic significance. Lab. Invest., 1964, 12, 1124-1138.

6) Hayashi, H., Kinuwaki, Y. \& Yoshinaga, M. Inhibition of anaphylactic release of vascular permeability factor or histamine by specific protease inhibitor in tissue culture. Nature, 1965, 208, 1007-1008.

7) Hayashi, H., Udaka, K., Miyoshi, H. \& Kudo, S. Further study of correlative behavior between specific protease and its inhibitor in cutaneous Arthus reactions. Lab. Invest., 1965, 14, 665-673.

8) Udaka, K. \& Hayashi, H. Further purification of a protease inhibitor from rabbit skin with healing inflammation. Biochim. biophys. Acta, 1965, 97, 251-261.

9) Udaka, K. \& Hayashi, H. Molecular-weight determination of a protease inhibitor from rabbit skin with healing inflammation. Biochim. biophys. Acta, 1965, 104, 600603.

10) Hayashi, H., Yoshinaga, M., Koono, M., Miyoshi, H. \& Matsumura, M. Endogeneous permeability factors and their inhibitors affecting vascular permeability in cutaneous Arthus reactions and thermal injury. Brit. J. exp. Path., 1964, 45, 419435.

11) Hayashi, H., Yoshinaga, M., Yamamoto, S., Hisaka, M. \& Tasaki, I. Inflammatory vascular permeability factors and their biologic significance. Myakkangaku (Jap.) $1965,5,81-85$.

12) Takaba, Y. Cytological study of antigen-antibody reaction in tissue culture. II. Cinemicrophotographic study of differences in early cellular damage by homologous antigen and by soluble antigen antibody complexes in tissue culture. Kumamoto med. $J ., 1965,18,31-40$.

13) Hayashi, H., Ono, T. \& Funaki, T. Experimental studies on rheumatic inflammation. VIII. Cytological studies on cellular antigen-antibody reaction in tissue culture (Report II). Observations using labeled antigen. Mie med. J., 1955, 4, Suppl. 2, 85-97. 


\section{Explanation of Figures}

Figs. 1-8. Sequences illustrating cellular changes after application of homologous antigen (BSA, $1.0 \mathrm{mg} \mathrm{N} / \mathrm{ml}$ ). Figs. 1-4 show an omental cell passively sensitized with $7 \mathrm{~S}$ antibody in vitro; Figs. 5-8 show the same type of cell similarly sensitized with $19 \mathrm{~S}$ antibody. Motion pictures were recorded at a speed of 30 frames per minute.

The changes in $7 \mathrm{~S}$-sensitized cell are characterized by 1) rapidly accelerated undulation of cell membrane followed by increased pinocytosis and 2) rapidly increased cytoplasmic current; such changes suggesting 'cellular excitation' began to decrease about 40 minutes after antigen. On the other hand, the changes in $19 \mathrm{~S}$-sensitized cell are characterized by 1) rapid stopping in cell membrane motion, pinocytosis and cytoplasmic flow and 2) coagulative change of cell membrane followed by macerated surface formation. 


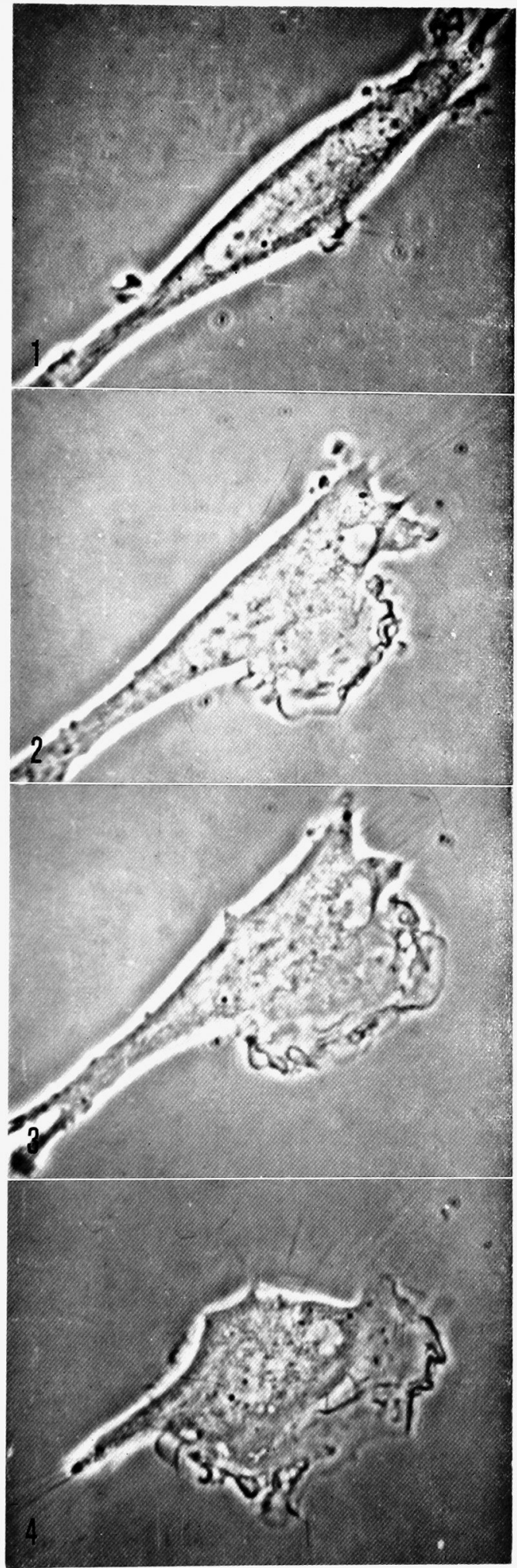

Fig. 1. Before entigen.

Fig. 2. 3 min astor antigen.

Fig. 3. 10 min aftei sntigen.

Fig. 4. $40 \mathrm{~min}$ after antigen 


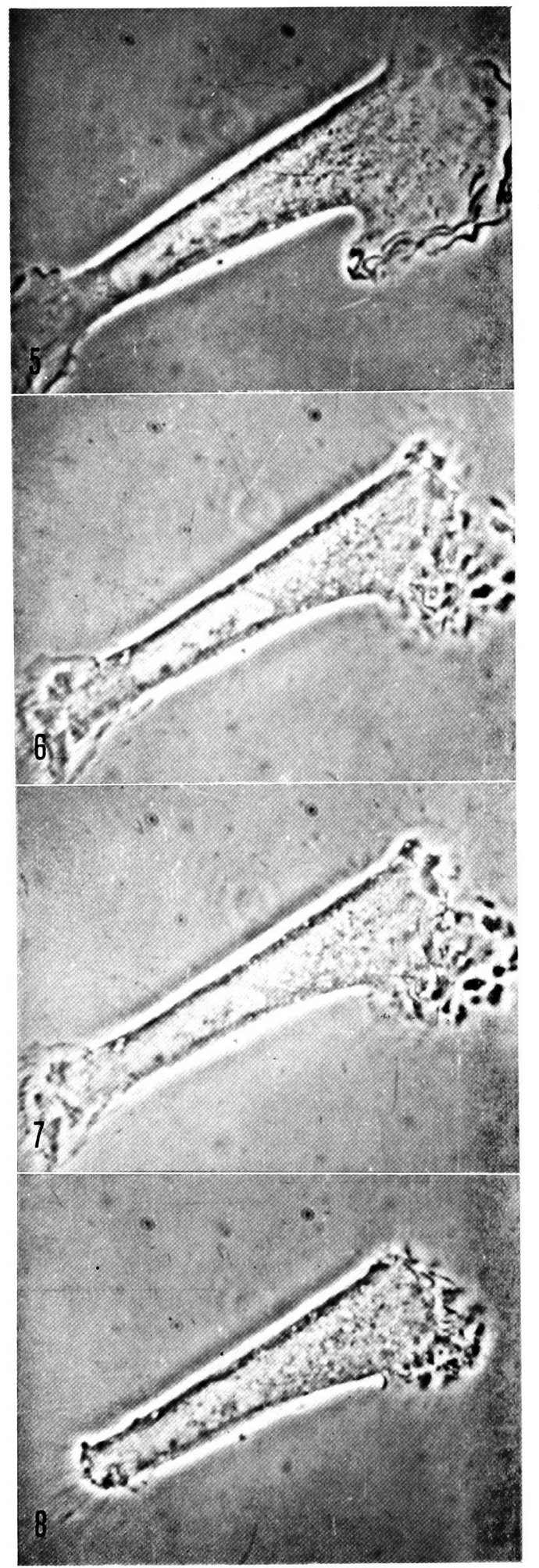

Fig. 5. Before antigen.

Fig. 6. 3 min after antigen.

Fig. 7. $10 \mathrm{~min}$ after antigen.

Fig. 8. 40 min after antigen. 